\title{
Retinoid Chemoprevention: Who Can Benefit?
}

\author{
Rodica P. Bunaciu ${ }^{1}$. Andrew Yen ${ }^{1}$
}

Published online: 14 April 2015

(C) Springer International Publishing AG 2015

\begin{abstract}
Acute promyelocytic leukemia (APL) is a treatment success story. From a highly deadly disease, it was turned into a highly curable disease by the introduction of differentiationinduction therapy with all-trans retinoic acid (ATRA) in the 1990s. During the last quarter of the century, ATRA and other retinoids were used for the treatment and prevention of other cancers and even other diseases. The results were less spectacular, but nevertheless important. Progress has been made toward understanding the mechanism of action of retinoids in different physiological and pathological contexts. For some diseases, specific genetic backgrounds were found to confer responsiveness to retinoid therapy. Therapies that include retinoids and other modalities are very diverse and used both for combined targeting of multiple pathways and for diminishing toxicity.
\end{abstract}

Keywords Retinoid · Chemoprevention · Retinoic acid signaling

\section{Introduction}

\section{Retinoids}

Vitamin A is a class of lipid-soluble essential micronutrients for all vertebrates [1]. "Vitamin A" is a generic term for all the

This article is part of the Topical Collection on Cancer Chemoprevention

Andrew Yen

ay13@cornell.edu

Rodica P. Bunaciu

rpb78@cornell.edu

1 Department of Biomedical Sciences, Cornell University, Ithaca, NY 14853, USA retinoids with the biological activity of all-trans retinol [2]. There are two main forms of dietary vitamin A: vitamin A (retinyl esters and retinol) and provitamin A carotenoids (beta-carotene, alpha-carotene, and beta-cryptoxanthin). Dietary precursors serve as substrates for the biosynthesis of two metabolites of vitamin A: 11-cis-retinal, essential for vision and all-trans retinoic acid (ATRA), essential for cell differentiation, cell survival, and the regulation of gene transcription. Retinol, retinal, and ATRA may be further metabolically modified, generating a myriad of retinoids with biological activities that are still to be fully elucidated. Besides the natural retinoids, structural analogs have also been synthesized. While natural products are metabolites/metabolizable, the synthetic ones typically are not.

\section{Retinoic Acid}

ATRA is the prototype for retinoid therapy and chemoprevention. It is an important developmental morphogen with pleiotropic actions. One of the most studied effects of retinoic acid in embryogenesis is the specification of the anterior-posterior axis and left-right patterning [3]. During development, retinoic acid gradients are controlled by the retinoic acid levels in the precursor cells and the expression of retinoic acid synthesizing (retinol dehydrogenase and aldehyde dehydrogenase) as well as degradation enzymes (Cyp26) [4-7]. Retinoic acid is important during developmental differentiation in many systems including hematologic and immune systems, eye, head, and heart [3]. Retinoic acid has well known chemopreventive effects in a variety of cancers [8-11]. It is also a teratogen [12-14]. Adults are also susceptible to side effects of excessive amounts of retinoic acid. For example, the adult hippocampus is very sensitive to extreme amounts of retinoic acid, as reviewed in [14], and differentiation syndrome (retinoic acid syndrome) is a life threatening 
pathological sequela of high doses of therapeutic retinoic acid, as reviewed in [15]. Many of the effects of extreme doses of retinoic acid are systemic, affecting many cell types and their interactions.

\section{Mechanisms of Action of Retinoids}

Although initially the biological effects of retinoic acid were rationalized to be due to cognate nuclear receptor-dependent direct regulation of transcription exclusively, accumulating evidence points out to a more complex reality. The mechanism of action of retinoic acid can now be categorized as nuclear and extranuclear. Furthermore, the nuclear effects could be categorized as transcriptional and epigenetic. The extranuclear effects can be categorized as plasma membrane derived or cytosolic.

\section{Transcriptional Regulation}

Retinoic acid and its metabolites, including its isomerization product, 9-cis-RA, and many synthetic retinoids are ligands for two classes of ligand-activated transcription factors, retinoic acid receptors (RARs) and retinoid X receptors (RXRs) $[16,17]$. RARs and RXRs present each three subtypes: alpha, beta, and gamma encoded by different genes [18]. RARs and RXRs are members of the superfamily of steroid thyroid hormone receptors. They can form homoand hetero-dimers. They bind DNA at hexad consensus sequences, AGGTCA, that occur in repeated (direct repeat, DR) or palindromic configurations separated by several nucleotides [18, 19], although exceptions are known [20]. 9-cisretinoic acid is capable of binding to the nuclear receptors and may be a major ligand of the RXRs. 13-cis-retinoic acid is effectively used as a therapeutic agent for dermatological diseases. It is present in human plasma and does not have high- affinity for RAR or RXR but localizes predominantly to the nuclei [21]. Numerous selective ligands have been synthesized with varying receptor specificity and biological responses.

RARs were reported to be phosphorylated, and the phosphorylation has functional consequences. For example, blocking the S77 RAR $\alpha$ phosphorylation contributes to Xeroderma pigmentosum pathology [22]. Retinoic acid induced neuronal differentiation requires RAR $\gamma$ phosphorylation [23]. RXR $\alpha$ is phosphorylated in response to UV radiations and $\mathrm{As}_{2} \mathrm{O}_{3}$ [24]. S22 RXR $\alpha$ and S369 RAR $\alpha$ phosphorylation are essential for cell cycle control and transcriptional regulation of target genes in F9 cells [25, 26].

Some genotypes of retinoid receptors, identified at the level of SNPs, are known to be risk factors for neoplasms or to affect response to retinoid chemoprevention and therapy. For example, the SNP rs3118570 in RXR $\alpha$ is correlated with increased risk for developing head and neck cancer, but the carriers of this genotype were shown to also benefit from retinoid chemoprevention [27].

\section{Epigenetic Regulation}

Recent research shows that retinoic acid induces profound epigenetic changes that are able to affect transcription other than by RAR and RXR direct transcriptional regulation by binding to cognate response elements. The RAR proteins are directly involved in inducing those changes by interacting with proteins of the transcription complex able to either place or remove epigenetic marks on histones or on DNA, recently reviewed by Gudas and collaborators [28].

Recent studies showed that inhibitors of lysine-specific demethylase 1 (LSD1) restored ATRA responsiveness in non-APL acute myelogenous leukemia (AML). LSD1 inhibition increased H3K4 (Me2) and expression of RA-dependent myeloid-differentiation-associated genes [29••]. Methylation of $\mathrm{CpG}$ islands at the promoter region of the HOXA gene cluster is increased in leukemia patients and leukemia cell lines, especially in T cell leukemia and B cell leukemia. In normal cells, the same region is unmethylated. In AML, ALL, and CML patients in complete remission and in RAtreated HL-60 and K562 cells, the methylation levels are downregulated [30].

Understanding epigenetic regulation induced by retinoids in more details is likely to improve therapies that seem promising, such as combination therapies including retinoids and valproic acid (currently recruiting patients clinical trials NCT00867672, NCT00995332, for example) or retinoids and LSD1 inhibitors such as tranylcypromine (currently recruiting patients clinical trial NCT02261779).

\section{Plasma Membrane-Derived Signaling}

Although ATRA binds both the RAR and RXR classes of receptors, it is found in higher concentrations outside the nucleus than inside, in contrast with 13-cis-retinoic acid which does not have high affinity for RAR or RXR but localizes predominantly to the nuclei [21]. More recently, it was shown that RAR $\alpha$ is present in the plasma membrane in a membrane lipid raft containing components of a MAPK signaling axis [31••]. Retinoic acid induces RAR $\alpha$ to complex with the G protein $\alpha \mathrm{Q}$ and to activate $\mathrm{p} 38 \mathrm{MAPK}$ [31••]. Additionally, p38MAPK further phosphorylates the nuclear pool of retinoic receptors, influencing their transcriptional activity [32].

\section{Cytosolic Signaling}

Retinoic acid elicits biological response through cytosolic signaling as well as the canonical interaction with RARs or RXRs. We and others have shown that the mechanism of 
action of RA-induced cell differentiation involves prolonged, hyperactive MAPK signaling and SFK signaling [33••, 34-39]. This presents the possibility of new targets of intervention for differentiation-induction therapy. Early studies demonstrating that MAPK involvement exploited HL-60 cells as an in vitro experimental model susceptible to molecular manipulation. The cells were derived from the blood of a leukemia patient from whom the leukemic cells capable of self-renewal were isolated. In vitro systems provide potent experimental means of gaining initial mechanistic insight for translation to in vivo clinical application. HL-60 is a myeloblastic leukemia cell line that is lineage uncommitted and capable of myeloid or monocytic differentiation in response to different agents. HL-60 is one of the standard NCI-60 cell lines, used for example in drug testing. It has been extensively used as a model for pharmacologically induced differentiation. HL-60 cells undergo myeloid differentiation with G0/G1 growth arrest, when treated with RA. This process requires sustained activation of MAPK signaling [40], and involves a cascade of signaling regulatory events including Src family kinases (Fgr and Lyn), p38, PI3K, c-Cbl, SLP-76, VAV1, CK2, KSR, as well as the IRF-1 transcription factor [33••, 41-44]. These are implicated as parts of a large signaling complex (signalsome) with RA-upregulated expression of its components. For a number of these putative signalsome components, their ability to drive differentiation has been directly demonstrated. For example, during RA-induced differentiation, ectopic expression of Raf [37, 45], Cbl [41], SLP-76 partnered with c-FMS [42], interferon regulatory factor 1 (IRF-1) [43], and aryl hydrocarbon receptor (AhR) [46] have been shown to enhance MAPK signal activation, in particular Raf activation, and to promote RAinduced differentiation and G0-arrest. Inclusion of IRF-1 as a functionally significant component of the signalsome was an unanticipated finding, but the interferon and RA pathways are known to cooperate [47], and this may be a novel part of the mechanism. In the case of AhR, which is a classical cognate transcription factor that binds XRE sites of target gene promoters, we found that RA-induced differentiation was dependent on its RA-induced upregulation [46]. We found that overexpression of AhR enhanced RA-induced differentiation. Furthermore, AhR upregulation caused Oct4 downregulation. Oct4 is a Yamanaka-Thomson transcription factor that confers pluripotency in iPS, and it is the one thus far found essential for driving reversion to stem cells from differentiated cells. RA thus induces formation of a putative signalsome in which a Raf/Mek/Erk axis is imbedded amidst adaptors, kinases, GEF, and transcription factors. These signalsome components are part of the mechanistic underpinnings of the prolonged hyperactive MAPK signal that drives cell differentiation. They are potential targets for augmenting RA effects as well as indicators of cellular response to RA.

\section{Retinoids in Treatment and Chemoprevention}

Chemoprevention is the use of drugs, food, or food supplements to prevent disease. The term includes but it is not limited to cancer. Chemoprevention by dietary factors can have a significant effect on the population by reducing cancer incidence in normal populations and relapse in former patients. A goal of cancer chemoprevention is to reverse or block the process of neoplastic transformation. In this regard, it can have several facets. In one paradigm, neoplastic transformations due to environment, for example, are constantly occurring but are reversed or lost and hence do not result in tumors. Thus, reversing the transformed phenotype is a form of chemoprevention, as is prevention of relapses [27]. In another perspective, processes directing stem-like cells, including those that seed to cause metastatic spread in a nurturing niche, to lose their self-renewal capability and assume a differentiated phenotype can also be considered chemopreventive. And any means of reversing the transformed phenotype or retarding tumorigenesis are in the broad sense all chemopreventive. Both of these instances provide motivation for trying to understand how a dietary factor can reverse the neoplastic phenotype, thereby providing early prevention. Such mechanistic insights are needed to find ways of enhancing this chemopreventive process. Frequently, mechanistic insights from therapeutic approaches provide valuable information for future chemoprevention modalities. Although there are many instances of retinoic acid chemopreventive effects, there are also enigmatic instances where it has had the opposite effect $[48,49]$.

Retinoids are used for treatment of a variety of conditions. The most successful is the differentiation therapy for APL. Currently, a number of ongoing clinical trials are using this differentiation modality in treating a large number of conditions. Some clinical trials have been withdrawn, such as NCT00003564 for glioma. However, this points to the need for detailed fuller understanding of the mechanism of action of retinoids to enhance their therapeutic and chemopreventive benefits.

\section{Acute Myelogenous Leukemia}

APL (AML3), a subtype of AML, is the success story for ATRA treatment [50]. About 25 years ago, APL was a fatal disease for most patients. Introduced in the late 1980s and early 1990s [50, 51], ATRA therapy induced high remission rates that were much higher remission rates achievable by chemotherapy alone, but the remission was not durable, and the relapsed APL- blasts were resistant to ATRA [52]. In the hope of alleviating relapses, combination therapy of ATRA and chemotherapy was used [52]. A recent study analyzing the dataset derived from the North American Intergroup Study INT0129 calculated for the first time the estimated duration of 
ATRA needed after chemotherapy to eliminate the leukemic stem population to a year [53]. This study authored by top experts in the field points out that ATRA can eliminate the cancer stem population by inducing differentiation of the blasts and modulating the cell cycle of the cancer stem cells. Prior to this, it was thought that ATRA could overcome a block in differentiation but did not eliminate the leukemic clone. In patients with relapsed APL, ATRA and arsenic trioxide was found to be effective [54]. Some experts therefore advocate a front line therapy of ATRA and arsenic trioxide without chemotherapy from the initial diagnosis for patients with low or intermediate risk APL [55-57]. In elderly APL patients or patients not qualifying for chemotherapy or arsenic trioxide therapy due to concurrent disease, ATRA as single therapy was proved to be effective in both induction and maintenance of remission $[58,59]$. In one such study, the regimen was ATRA ( $45 \mathrm{mg} / \mathrm{m}^{2} /$ day) for 21 days, then 1 week every 2 weeks (pulsed ATRA) [58]. An earlier study established that a single oral ATRA dose of $15 \mathrm{mg} / \mathrm{m}^{2}$ led to a plasma concentration of $1 \mu \mathrm{M}$, a concentration sufficient to induce APL blast differentiation [60]. However, a practical problem encountered clinically is that plasma levels of ATRA drop after prolonged treatment. Liposomal ATRA was shown to better maintain plasma levels of ATRA and induce a more durable remission as a single agent $[61,62]$.

The traditional inclusion criteria for ATRA treatment were the RAR fusion proteins characteristic of APL. More recently, however, the use of ATRA treatment is being expanded to other AMLs.

Adult patients with AML and NPM1 mutations who are ineligible for intensive chemotherapy, especially elderly patients, might benefit from chemotherapy with cytarabine, etoposide, and retinoic acid. A clinical trial of this type that is recruiting patients is NCT01237808. Another clinical trial, NCT00892190 "Study of Dasatinib and All-Trans Retinoic Acid for Relapsed/Refractory and/or Elderly Patients with Acute Myelogenous Leukemia (AML) or Myelodysplastic Syndrome (MDS)", is also recruiting patients. We and others have provided evidence that combination therapy of retinoic acid plus SFK inhibitors targets critical cytosolic signaling components, and this could be of therapeutic benefit [33••, 63]. Another proposed combination therapy with ATRA in non-APL AML patients uses ATRA with valproic acid. In this case, there are two patient recruiting clinical trials, NCT00867672 and NCT00995332, being conducted in Germany. We had shown that valproic acid with retinoic acid enhances RA-induced differentiation and cell cycle arrest by upregulating $\mathrm{AhR}$ and consequently downregulating Oct4 in an AML cell line model, HL-60 [46]. Also, in non-APL AML subtypes, tranylcypromine (TCP), an irreversible monoamineoxidase (MAO) and lysin-specific demethylase (LSD) inhibitor that also inhibits LSD1 (a histone H3 lysine 4 demethylase), induces blast cell differentiation and leukemic stem cell exhaustion in vitro and in vivo with RA [29••, 64]. A related clinical trial, NCT02261779 is recruiting patients.

The phase II clinical trial NCT00326170 was an interventional UT MD Anderson Cancer Center study for patients with refractory or relapsed MDS and AML. 5-azacytidine (5-aza) and valproic acid were coadministered with ATRA. The hypothesis was that cotreatment of a DNA hypomethylating agent along with a histone deacetylase inhibitor plus ATRA will restore ATRA responsiveness in resistant cells. The response rate was $42 \%$ and the median remission was 26 weeks [65].

The success of treating some AML cases with ATRA5 -azacytidine combination therapy increased efforts to determine the mechanism of action underlying this effect. Olfactomedin 4 (OLFM4 also known as GCSF-stimulated clone 1 , hGC-1, or GW112) was found to be one of the targets regulated by this combination therapy [66]. Using non-APL- AML patient samples and the HL-60 cell line, it was found that the OLFM4 gene has a DR5 site in its promoter that is negatively regulated by methylation to which the $\operatorname{RAR} \alpha / \operatorname{RXR} \alpha$ heterodimer binds [66]. A downstream effect of OLFM4 is the inhibition of cap-dependent mRNA protein initiation. By overexpression and knockdown studies, it was shown that OLFM4 expression enhances differentiation and apoptosis of AML cells [66]. OLFM4 is likely not the only target of ATRA in RAresponsive AML-including non-APL subtypes of AML. Nevertheless, it is a prototype that encourages the search for a fuller understanding of the mechanism of action of ATRA in successful treatment regimens so that combination therapy with ATRA can be extended to other cancer types. However, for colorectal [67, 68], endometrial adenocarcinoma [69], solid gastric, pancreatic, and head and neck [68] cancers, high level of OLFM4 is a negative prognostic factor. For prostate cancer, the deletion of OLFM4 gene was reported to be associated with tumor progression [70]. This further points to the role of gene regulation for optimal levels of protein expression and tissue specificity. Moreover, OLFM4, being RA regulated, points to the need of understanding in greater detail the RA-induced proteomic changes in different tissues. This is needed in order to expand and optimize RA chemoprevention and treatment applications.

\section{Neuroblastoma}

In children with high-risk neuroblastoma, 13-cis-RA plus immunotherapy with anti-GD2 is the standard treatment for minimal residual disease [71]. In chemoresistant osteomedullary neuroblastoma, 13-cis-RA with anti-GD2 antibody and granulocyte-macrophage colony-stimulating factor are clinically effective by augmenting the antineoplastic potency of the myeloid effectors [72]. Patients with neuroblastoma have 
an increased risk of secondary neoplasia, especially acute myeloid leukemia/myelodysplastic syndrome [73]. The fact that those malignancies are responsive to retinoids and the fact that a history of neuroblastoma predisposes to AML or myelodysplastic syndrome points to the fact that the etiology involves possibly a disruption in RA signaling pathways, and that those pathways and retinoid chemoprevention (alone or in combination with other agents) needs to be further investigated by detailed mechanistic studies.

\section{Breast Cancer}

An interesting characteristic of retinoid use for breast cancer management is the wide variety of the mechanisms of action proposed and the discrepancy between a large number of preclinical trials and very limited clinical trials for retinoic and breast. On clinicaltrials.gov site, there are just two clinical trials listed plus those completed and with no results listed. Additionally, there are some clinical trials on chemoprevention conferred by retinoids and breast is included among other sites studies, studies done both in the USA and in Italy [74]. A recent review assessed the current understanding for retinoid chemoprevention and therapy for breast cancer [75].

\section{Cervical Cancer}

As reviewed by Helm et al. [76], various retinoids (natural: 9-cis-RA, 13-cis-RA, ATRA, and synthetic: $\mathrm{N}$-(4-hydroxyphenyl)retinamide) were tested. Different doses, routes, and intervals of administration tested were not significantly effective in causing regression or prevent progression of invasive cervical carcinoma. $\mathrm{N}$-(4hydroxyphenyl)retinamide caused a worse outcome (absence of desired effects in a small sample set) for the patients in the treatment group than in placebo, and the study was terminated early [77].

\section{Lung Cancer}

An interventional study was conducted under the phase II clinical trial NCT00062010. Patients with recurrent small cell lung cancer were treated with IFN $\alpha$, isotretinoin, and paclitaxel. The overall response percentage was $8.8 \%$. The median survival was 6.2 months and the median progression-free survival was 2 months. Participants were recruited from Eastern Cooperative Oncology Group member institutions between February 24, 2004 and August 22, 2007. The rationale for adding the retinoid was to reduce resistance to paclitaxel.

In another clinical trial, NCT00601796, conducted at the H. Lee Moffitt Cancer Center and Research Institute, ATRA $\left(150 \mathrm{mg} / \mathrm{m}^{2} /\right.$ day given orally three times a day for three consecutive days in two courses, during week 1 and week 9) was added to cyclophosphamide and a vaccine regimen in order to enhance dendritic differentiation. The vaccine was made using irradiated allogeneic lung adenocarcinoma cells and K562 cell line transfected with hCD40L and hGM-CSF. The hypothesis was that by recruiting and activating the dendritic cells, the treatment would induce tumor regression in refractory lung adenocarcinoma. The median progression-free survival was 1.7 months and the median overall survival was 7.9 months. There was no radiologic tumor regression achieved [78].

\section{Hepatocellular Carcinoma}

TAC-101, a synthetic retinoid, administrated $20 \mathrm{mg}$ /day orally led to disease stabilization and prolonged median survival (19.2 months) in patients with advanced hepatocellular carcinoma [79].

\section{Head and Neck Cancer}

The first line of treatment for head and neck squamous cell carcinoma (HNSCC) is surgery and/or radiation therapy. Within 5 years, however, $10-25 \%$ of the treated patients develop recurrence or second primary tumors. Common sites for second primary tumor in the HNSCC survivors are the esophagus and the lung [80, 81]. 13-cis-retinoic acid was tested as a chemopreventive agent to prevent both recurrent and second primary tumors. Daily doses of 50-100 mg $13-c i s-\mathrm{RA} / \mathrm{m}^{2} /$ day for 12 months prevented second primary tumors but had no effect on recurrence in patients treated for HNSCC [82, 83]. The 13-cis-RAdependent side effects (skin dryness, cheilitis, hypertriglyceridemia, and conjunctivitis) at those doses were very severe [82]. After the completion of the 13-cis-retinoic acid administration, its chemopreventive effect against second primary tumors diminishes in time [83]. A randomized, placebocontrolled trial of daily low-dose $\left(30 \mathrm{mg} / \mathrm{m}^{2} /\right.$ day $) 13$-cis-RA administrated for 3 years followed by 4 years of observation was conducted in a population of survivors of HNSCC treated for early stage disease [84]. In this group of population, overall, $31 \%$ developed SPT/recurrence in the 13-cis-RA vs $35 \%$ in the placebo. However, the SNP rs 3118570 in RXR $\alpha$ is correlated with both increased risk for developing head and neck cancer, and benefit from retinoid chemoprevention. This genotype represented $71 \%$ of the population in the placebo group. Additionally, patients with certain genotypes of Janus kinase 2 (JAK2), matrix metallopeptidase 3 (MMP3), RAD-54-like (RAD54L), and cell division cycle 25 homolog C (CDC25C) were 1.85-3.57 times more likely to develop an SPT/recurrence, compared with patients who had variant containing genotypes JAK2:rs188724 and CDC25C:rs6896428 being predictors for 13-cis-response as well [27]. Likewise, the SNPs rs739442, rs4962225, rs7035940, and rs7874234 in TSC1 and PI3KCD:rs4129341 and PTEN:rs1234221 confer highrisk of SPT/high-benefit for 13-cis-RA chemoprevention [85]. 


\section{Alzheimer's Disease}

ATRA, 9-cis-RA, and 13-cis-RA are promising agents for prevention of Alzheimer's disease. The mechanism likely involves RAR- and RXR-dependent regulation of apolipoprotein $\mathrm{E}$ [86]. The synthetic retinoid acitretin is a promising drug for the treatment of Alzheimer's disease by its ability to enhance the nonamyloidogenic amyloid precursor protein (APP) processing [87].

\section{Dermatological Conditions}

In dermatological conditions, retinoids have a long history of applications. A detailed systematic description of those applications is beyond the scope of this review. Here, we present a few examples in order to give a sense of the diversity of the retinoid applications. Xeroderma pigmentosum is a rare genetic disorder. One of its characteristics is a mutated TFIIH transcription factor. This leads to impaired RAR $\alpha$ phosphorylation and therefore impaired ligand-dependent control of the activation of the hormone-responsive genes [22]. Anti-psoriatic synthetic retinoid tazarotene, AGN 190168/ethyl 6-[2-(4,4-dimethylthiochroman-6-yl)-ethynyl] nicotinate, is a RAR $\beta$ and $\operatorname{RAR} \gamma$ agonist which upregulates tazarotene-induced gene 2 (TIG2) protein in psoriatic lesions toward the levels found in normal skin [88]. Tezarotene-induced TIG3 seems to suppress inflammatory angiogenesis by downregulating PIGF expression, in psoriatic lesions [89]. Randomized, doubleblind, vehicle-controlled, parallel-group studies led at 39 centers in the USA and Canada found that foam containing $0.1 \%$ tazarotene significantly reduced the number and severity of acne lesions after 3 months [90]. Adapalene is a synthetic retinoid that diminishes the number of lesions [91]. Currently, a clinical trial (NCT02173054) is recruiting acne patients. In certain cases, retinoids are useful in treating mycosis fungoides [92]. Chronic eczema is treated with 9-cis-RA, and one of the mechanisms involved is an increase of FoxP3 cells in the skin [93]. In dissecting cellulitis, topical 13-cis-RA is the most effective drug to induce remission [94]. The synthetic retinoid acitretin is effective in treating psoriasis $[95,96]$, although its mechanism of action is not fully understood. Effects on metabolism were proposed [97-99].

\section{Conclusions}

Recent research has demonstrated that multiple mechanisms account for retinoid chemopreventive and therapeutic effects. Despite the common perception that retinoid therapy is successful just in the case of APL and skin diseases, recent evidence shows that retinoids are valuable therapeutic and chemopreventive agents. Progress in the detailed mechanism of action of retinoids is likely to extend the benefits of retinoids and to develop more specific and less invasive means of chemoprevention and therapy. Finding the biomarkers of enhanced response or resistance is very important toward achieving personalized medicine. A very important point is made by Formelli [74] regarding the interdependence of the time of administration of retinoids, diet, retinoid serum levels, and effects. It is of interest that he points out that in cohorts of people taking oral retinoids after diner, the serum levels are much higher and this effect is especially prevalent in populations habitually consuming important quantities of olive oil. This is not unexpected as retinoids are lipidsoluble; however, it is an often ignored detail in retinoid clinical trials. Additionally, we and others have reported that different oils have different effects on cell proliferation or differentiation, endpoints often targeted by retinoid chemoprevention [100-104]. This points to the need of future studies of retinoid cellular and systemic effects and mechanism of action where other relevant factors such as diet are carefully controlled. On the other hand, there are recent efforts being made to use diet and dietary supplements for ameliorating the retinoid-induced side effects [105]. Detailed mechanistic insight of retinoid effects will likely reveal points of further modulation by dietary or pharmacological agents for enhanced chemopreventive/therapeutic benefit. There are many other conditions in which retinoids have a potential to be chemopreventive; the examples given here are meant to raise awareness of the complexity of this field and to point out that despite a common perception that the field is mature and understood, there are many benefits of retinoids, many struggles in understanding the balance between benefits and risks, and a wide variety of biological processes modulated by retinoids, encompassing but clearly not limited to the retinoid receptors.

We regret it was not possible to cite all of the important work that has been reported in this broad and active field and apologize for omissions.

Acknowledgments We gratefully acknowledge partial support from the National Institutes of Health (NIH) CA033505 (Yen), CA152870 (Yen), 1U54 CA143876 (Shuler), and New York State Stem Cell Science (NYSTEM) (Yen).

\section{Compliance with Ethics Guidelines}

Conflict of Interest Rodica P. Bunaciu and Andrew Yen declare that they have no conflict of interest.

Human and Animal Rights and Informed Consent This article does not contain any studies with human or animal subjects performed by any of the authors 


\section{References}

Papers of particular interest, published recently, have been highlighted as:

- Of major importance

1. Zempleni J, Rucker RB, Suttie JW, McCormick DB. Handbook of Vitamins. 4th ed. Boca Raton: CRC Press; 2007.

2. Liebecq C. IUPAC-IUBMB Joint Commission on Biochemical Nomenclature (JCBN) and Nomenclature Committee of IUBMB (NC-IUBMB). Newsletter 1996. Eur J Biochem / FEBS. 1997;247:733-9.

3. Gilbert SF. Developmental Biology. 9th ed. Sunderland: Sinauer Associates, Inc.; 2010.

4. Uehara M, Yashiro K, Takaoka K, Yamamoto M, Hamada H. Removal of maternal retinoic acid by embryonic CYP26 is required for correct Nodal expression during early embryonic patterning. Genes Dev. 2009;23:1689-98.

5. Sandell LL, Sanderson BW, Moiseyev G, Johnson T, Mushegian A, Young K, et al. RDH10 is essential for synthesis of embryonic retinoic acid and is required for limb, craniofacial, and organ development. Genes Dev. 2007;21:1113-24.

6. Sakai Y, Meno C, Fujii H, Nishino J, Shiratori H, Saijoh Y, et al. The retinoic acid-inactivating enzyme CYP26 is essential for establishing an uneven distribution of retinoic acid along the anterioposterior axis within the mouse embryo. Genes Dev. 2001;15: 213-25.

7. Oosterveen T, Meijlink F, Deschamps J. Expression of retinaldehyde dehydrogenase II and sequential activation of $5^{\prime}$ Hoxb genes in the mouse caudal hindbrain. Gene Expr Patterns. 2004;4:243-7.

8. Niles RM. Signaling pathways in retinoid chemoprevention and treatment of cancer. Mutat Res. 2004;555:81-96.

9. Shen PF. Molecular mechanisms of chemoprevention and therapy of cancer by retinoids. Front Biosci J Virtual Libr. 2004;9: 2663-70.

10. Okuno M, Kojima S, Matsushima-Nishiwaki R, Tsurumi H, Muto Y, Friedman SL, et al. Retinoids in cancer chemoprevention. Curr Cancer Drug Targets. 2004;4:285-98.

11. Kakizoe T. Chemoprevention of cancer-focusing on clinical trials. Jpn J Clin Oncol. 2003;33:421-42.

12. Hierck BP, Gittenberger-de Groot AC, van Iperen L, Brouwer A, Poelmann RE. Expression of the beta 4 integrin subunit in the mouse heart during embryonic development: retinoic acid advances beta 4 expression. Dev Dyn Off Publ Am Assoc Anatomists. 1996;207:89-103.

13. Hand JL. Retinoic acid: a familiar teratogen. Pediatr Dermatol. 2012;29:774-6.

14. McCaffery PJ, Adams J, Maden M, Rosa-Molinar E. Too much of a good thing: retinoic acid as an endogenous regulator of neural differentiation and exogenous teratogen. Euro J Neurosci. 2003; 18:457-72.

15. Tariq Z, Phinney RC, Mohamed I. A case of life-threatening retinoic acid syndrome and review of literature. Am J Ther. 2014;21:e28-30.

16. Mangelsdorf DJ, Ong ES, Dyck JA, Evans RM. Nuclear receptor that identifies a novel retinoic acid response pathway. Nature. 1990;345:224-9.

17. Mangelsdorf DJ, Borgmeyer U, Heyman RA, Zhou JY, Ong ES, Oro AE, et al. Characterization of three RXR genes that mediate the action of 9-cis retinoic acid. Genes Dev. 1992;6:329-44.

18. Germain P, Chambon P, Eichele G, Evans RM, Lazar MA, Leid $\mathrm{M}$, et al. International Union of Pharmacology. LX. Retinoic Acid Recept Pharmacol Rev. 2006;58:712-25.
19. Mangelsdorf DJ, Evans RM. The RXR heterodimers and orphan receptors. Cell. 1995;83:841-50.

20. Wang J, Yen A. A novel retinoic acid-responsive element regulates retinoic acid-induced BLR1 expression. Mol Cell Biol. 2004;24: 2423-43.

21. Ruhl R, Plum C, Elmazar MM, Nau H. Embryonic subcellular distribution of 13-cis- and all-trans-retinoic acid indicates differential cytosolic/nuclear localization. Toxicol Sci Off J Soc Toxicol. 2001;63:82-9.

22. Keriel A, Stary A, Sarasin A, Rochette-Egly C, Egly JM. XPD mutations prevent TFIIH-dependent transactivation by nuclear receptors and phosphorylation of RARalpha. Cell. 2002;109:125-35.

23. Al Tanoury Z, Gaouar S, Piskunov A, Ye T, Urban S, Jost B, et al. Phosphorylation of the retinoic acid receptor RARgamma2 is crucial for the neuronal differentiation of mouse embryonic stem cells. J Cell Sci. 2014;127:2095-105.

24. Bruck N, Bastien J, Bour G, Tarrade A, Plassat JL, Bauer A, et al. Phosphorylation of the retinoid $\mathrm{x}$ receptor at the omega loop, modulates the expression of retinoic-acid-target genes with a promoter context specificity. Cell Signal. 2005;17:1229-39.

25. Bastien J, Adam-Stitah S, Plassat JL, Chambon P, Rochette-Egly C. The phosphorylation site located in the A region of retinoic $\mathrm{X}$ receptor alpha is required for the antiproliferative effect of retinoic acid (RA) and the activation of RA target genes in F9 cells. J Biol Chem. 2002;277:28683-9.

26. Rochette-Egly C, Oulad-Abdelghani M, Staub A, Pfister V, Scheuer I, Chambon P, et al. Phosphorylation of the retinoic acid receptor-alpha by protein kinase A. Mol Endocrinol. 1995;9:860-71.

27. Lee JJ, Wu X, Hildebrandt MA, Yang H, Khuri FR, Kim E, et al. Global assessment of genetic variation influencing response to retinoid chemoprevention in head and neck cancer patients. Cancer Prev Res (Phila). 2011;4:185-93.

28. Urvalek A, Laursen KB, Gudas LJ. The roles of retinoic acid and retinoic acid receptors in inducing epigenetic changes. Subcell Biochem. 2014;70:129-49.

29.• Schenk T, Chen WC, Gollner S, Howell L, Jin L, Hebestreit K, et al. Inhibition of the LSD1 (KDM1A) demethylase reactivates the all-trans-retinoic acid differentiation pathway in acute myeloid leukemia. Nat Med. 2012;18:605-11. This paper identifies LSD1 as a therapeutic target and contributor to AML pathogenesis by inhibiting the normal pro-differentiative function of ATRA.

30. Fang MH, Liu WL, Meng FK, Sun HY. Aberrant methylation at promoter region of HOX A gene cluster in leukemia cells. Zhonghua Xue Ye Xue Za Zhi = Zhonghua Xueyexue Zazhi. 2009;30:468-72.

31.• Piskunov A, Rochette-Egly C. A retinoic acid receptor RARalpha pool present in membrane lipid rafts forms complexes with $\mathrm{G}$ protein alphaQ to activate p38MAPK. Oncogene. 2012;31: $3333-45$. The paper identified a pool of RAR $\alpha$ in the plasma membrane lipid rafts and reported $\mathrm{G}$ protein $\alpha \mathrm{Q}$ as a new RAR $\alpha$ interacting protein. Both RAR $\alpha$ and $G \alpha q$ were found to mediate the activation of p38MAPK, with downstream consequences on cell growth.

32. Piskunov A, Al Tanoury Z, Rochette-Egly C. Nuclear and extranuclear effects of retinoid acid receptors: how they are interconnected. Subcell Biochem. 2014;70:103-27.

33.• Congleton J, MacDonald R, Yen A. Src inhibitors, PP2 and dasatinib, increase retinoic acid-induced association of Lyn and c-Raf (S259) and enhance MAPK-dependent differentiation of myeloid leukemia cells. Leuk Off J Leuk Soc Am Leuk Res Fund UK. 2012;26:1180-8. This paper provides mechanistic insight for SFK inhibitors' benefit in ATRA therapy. 
34. Geil WM, Yen A. Nuclear Raf-1 kinase regulates CXCR5 promoter by associating with NFATc3 to drive retinoic acid-induced leukemic cell differentiation. FEBS J. 2014;281:1170-80.

35. Smith J, Bunaciu RP, Reiterer G, Coder D, George T, Asaly M, et al. Retinoic acid induces nuclear accumulation of Rafl during differentiation of HL-60 cells. Exp Cell Res. 2009;315:2241-8.

36. Yen A, Varvayanis S. Retinoic acid increases amount of phosphorylated RAF; ectopic expression of cFMS reveals that retinoic acidinduced differentiation is more strongly dependent on ERK2 signaling than induced GO arrest is. In Vitro Cell Dev Biol Anim. 2000;36:249-55.

37. Yen A, Williams M, Platko JD, Der C, Hisaka M. Expression of activated RAF accelerates cell differentiation and RB protein down-regulation but not hypophosphorylation. Eur J Cell Biol. 1994;65:103-13.

38. Congleton J, Shen M, MacDonald R, Malavasi F, Yen A. Phosphorylation of c-Cbl and $\mathrm{p} 85 \mathrm{PI} 3 \mathrm{~K}$ driven by all-trans retinoic acid and CD38 depends on Lyn kinase activity. Cell Signal. 2014;26:1589-97.

39. Katagiri K, Yokoyama KK, Yamamoto T, Omura S, Irie S, Katagiri T. Lyn and Fgr protein-tyrosine kinases prevent apoptosis during retinoic acid-induced granulocytic differentiation of HL-60 cells. J Biol Chem. 1996;271:11557-62.

40. Yen A, Roberson MS, Varvayanis S, Lee AT. Retinoic acid induced mitogen-activated protein (MAP)/extracellular signalregulated kinase (ERK) kinase-dependent MAP kinase activation needed to elicit HL-60 cell differentiation and growth arrest. Cancer Res. 1998;58:3163-72.

41. Shen M, Yen A. c-Cbl interacts with CD38 and promotes retinoic acid-induced differentiation and G0 arrest of human myeloblastic leukemia cells. Cancer Res. 2008;68:8761-9.

42. Yen A, Varvayanis S, Smith JL, Lamkin TJ. Retinoic acid induces expression of SLP-76: expression with c-FMS enhances ERK activation and retinoic acid-induced differentiation/G0 arrest of HL-60 cells. Eur J Cell Biol. 2006;85:117-32.

43. Shen M, Bunaciu RP, Congleton J, Jensen HA, Sayam LG, Varner $\mathrm{JD}$, et al. Interferon regulatory factor-1 binds c-Cbl, enhances mitogen activated protein kinase signaling and promotes retinoic acid-induced differentiation of HL-60 human myelo-monoblastic leukemia cells. Leuk Lymphoma. 2011;52:2372-9.

44. Marchisio M, Bertagnolo V, Colamussi ML, Capitani S, Neri LM. Phosphatidylinositol 3-kinase in HL-60 nuclei is bound to the nuclear matrix and increases during granulocytic differentiation. Biochem Biophys Res Commun. 1998;253:346-51.

45. Wang J, Yen A. A MAPK-positive feedback mechanism for BLR1 signaling propels retinoic acid-triggered differentiation and cell cycle arrest. J Biol Chem. 2008;283:4375-86.

46. Bunaciu RP, Yen A. Activation of the aryl hydrocarbon receptor AhR promotes retinoic acid-induced differentiation of myeloblastic leukemia cells by restricting expression of the stem cell transcription factor Oct4. Cancer Res. 2011;71:2371-80.

47. Matikainen S, Ronni T, Hurme M, Pine R, Julkunen I. Retinoic acid activates interferon regulatory factor-1 gene expression in myeloid cells. Blood. 1996;88:114-23.

48. Di Bisceglie AM, Osmack P, Brunt EM. Chemoprevention of hepatocellular carcinoma: use of tamoxifen in an animal model of hepatocarcinogenesis. J Lab Clin Med. 2005;145:134-8.

49. Khuri FR, Lippman SM. Lung cancer chemoprevention. Semin Surg Oncol. 2000;18:100-5.

50. Douer D, Zickl LN, Schiffer CA, Appelbaum FR, Feusner JH, Shepherd L, et al. All-trans retinoic acid and late relapses in acute promyelocytic leukemia: very long-term follow-up of the North American Intergroup Study I0129. Leuk Res. 2013;37:795-801.

51. Huang ME, Ye YC, Chen SR, Chai JR, Lu JX, Zhoa L, et al. Use of all-trans retinoic acid in the treatment of acute promyelocytic leukemia. Blood. 1988;72:567-72.
52. Cornic M, Delva L, Castaigne S, Lefebvre P, Balitrand N, Degos $\mathrm{L}$, et al. In vitro all-trans retinoic acid (ATRA) sensitivity and cellular retinoic acid binding protein (CRABP) levels in relapse leukemic cells after remission induction by ATRA in acute promyelocytic leukemia. Leuk Off J Leuk Soc Am Leuk Res Fund UK. 1994;8:914-7.

53. Werner B, Gallagher RE, Paietta EM, Litzow MR, Tallman MS, Wiernik PH, et al. Dynamics of leukemia stem-like cell extinction in acute promyelocytic leukemia. Cancer Res. 2014;74:5386-96.

54. Daver N, Kantarjian H, Marcucci G, Pierce S, Brandt M, Dinardo $\mathrm{C}$, et al. Clinical characteristics and outcomes in patients with acute promyelocytic leukaemia and hyperleucocytosis. Br J Haematol. 2015;168:646-53.

55. Efficace F, Mandelli F, Avvisati G, Cottone F, Ferrara F, Di Bona $\mathrm{E}$, et al. Randomized phase III trial of retinoic acid and arsenic trioxide versus retinoic acid and chemotherapy in patients with acute promyelocytic leukemia: health-related quality-of-life outcomes. J Clin Oncol Off J Am Soc Clin Oncol. 2014;32:3406-12.

56. Lo-Coco F, Cicconi L. What is the standard regimen for patients with acute promyelocytic leukemia? Curr Hematol Malig Rep. 2014;9:138-43.

57. Huang BT, Zeng QC, Zhao WH, Li BS, Chen RL. A prospective, observational study of added medium-dose cytosine arabinoside versus As2O3 for elderly patients with acute promyelocytic leukemia. Med Oncol. 2014;31:233.

58. Visani G, Buonamici S, Malagola M, Isidori A, Piccaluga PP, Martinelli G, et al. Pulsed ATRA as single therapy restores longterm remission in PML-RARalpha-positive acute promyelocytic leukemia patients: real time quantification of minimal residual disease. A pilot study. Leuk Off J Leuk Soc Am Leuk Res Fund UK. 2001;15:1696-700.

59. Finsinger P, Breccia M, Minotti C, Carmosino I, Girmenia $\mathrm{C}$, Chisini $\mathrm{M}$, et al. Acute promyelocytic leukemia in patients aged >70 years: the cure beyond the age. Ann Hematol. 2015;94: 195-200.

60. Chen GQ, Shen ZX, Wu F, Han JY, Miao JM, Zhong HJ, et al. Pharmacokinetics and efficacy of low-dose all-trans retinoic acid in the treatment of acute promyelocytic leukemia. Leuk Off J Leuk Soc Am Leuk Res Fund UK. 1996;10:825-8.

61. Estey EH, Giles FJ, Kantarjian H, O'Brien S, Cortes J, Freireich EJ, et al. Molecular remissions induced by liposomal-encapsulated all-trans retinoic acid in newly diagnosed acute promyelocytic leukemia. Blood. 1999;94:2230-5.

62. Douer D, Estey E, Santillana S, Bennett JM, Lopez-Bernstein G, Boehm K, et al. Treatment of newly diagnosed and relapsed acute promyelocytic leukemia with intravenous liposomal all-trans retinoic acid. Blood. 2001;97:73-80.

63. Fang Y, Zhong L, Lin M, Zhou X, Jing H, Ying M, et al. MEK/ ERK dependent activation of STAT1 mediates dasatinib-induced differentiation of acute myeloid leukemia. PLoS One. 2013;8: e66915.

64. Harris WJ, Huang X, Lynch JT, Spencer GJ, Hitchin JR, Li Y, et al. The histone demethylase KDM1A sustains the oncogenic potential of MLL-AF9 leukemia stem cells. Cancer Cell. 2012;21: 473-87.

65. Soriano AO, Yang H, Faderl S, Estrov Z, Giles F, Ravandi F, et al. Safety and clinical activity of the combination of 5-azacytidine, valproic acid, and all-trans retinoic acid in acute myeloid leukemia and myelodysplastic syndrome. Blood. 2007;110:2302-8.

66. Liu W, Lee HW, Liu Y, Wang R, Rodgers GP. Olfactomedin 4 is a novel target gene of retinoic acids and 5-aza-2'-deoxycytidine involved in human myeloid leukemia cell growth, differentiation, and apoptosis. Blood. 2010;116:4938-47.

67. Karagiannis GS, Pavlou MP, Saraon P, Musrap N, Xie A, Batruch I, et al. In-depth proteomic delineation of the colorectal cancer 
exoproteome: mechanistic insight and identification of potential biomarkers. J Proteome. 2014;103:121-36.

68. Guette C, Valo I, Vetillard A, Coqueret O. Olfactomedin-4 is a candidate biomarker of solid gastric, colorectal, pancreatic, head and neck, and prostate cancers. Proteomics Clin Appl. 2015;9:58-63.

69. Duan C, Liu X, Liang S, Yang Z, Xia M, Wang L, et al. Oestrogen receptor-mediated expression of Olfactomedin 4 regulates the progression of endometrial adenocarcinoma. J Cell Mol Med. 2014;18:863-74.

70. Li H, Rodriguez-Canales J, Liu W, Zhu J, Hanson JC, Pack S, et al. Deletion of the olfactomedin 4 gene is associated with progression of human prostate cancer. Am J Pathol. 2013;183:132938.

71. Veal GJ, Errington J, Rowbotham SE, Illingworth NA, Malik G, Cole M, et al. Adaptive dosing approaches to the individualization of 13-cis-retinoic acid (isotretinoin) treatment for children with high-risk neuroblastoma. Clin Cancer Res Off J Am Assoc Cancer Res. 2013;19:469-79.

72. Cheung NK, Cheung IY, Kramer K, Modak S, Kuk D, PanditTaskar N, et al. Key role for myeloid cells: phase II results of antiG(D2) antibody 3F8 plus granulocyte-macrophage colony-stimulating factor for chemoresistant osteomedullary neuroblastoma. Int J Cancer J Int Du Cancer. 2014;135:2199-205.

73. Federico SM, Allewelt HB, Spunt SL, Hudson MM, Wu J, Billups $\mathrm{CA}$, et al. Subsequent malignant neoplasms in pediatric patients initially diagnosed with neuroblastoma. J Pediatr Hematol Oncol Off J Am Soc Pediatr Hematol Oncol. 2015;37:e6-12.

74. Formelli F. Correspondence re: M. Follen et al., a randomized clinical trial of 4-hydroxyphenylretinamide for high-grade squamous intraepithelial lesions of the cervix. Clin Cancer Res Off J Am Assoc Cancer Res. 2002;8:1310-2. author reply 1313.

75. Garattini E, Bolis M, Garattini SK, Fratelli M, Centritto F, Paroni $\mathrm{G}$, et al. Retinoids and breast cancer: from basic studies to the clinic and back again. Cancer Treat Rev. 2014;40:739-49.

76. Helm CW, Lorenz DJ, Meyer NJ, Rising WW, Wulff JL. Retinoids for preventing the progression of cervical intraepithelial neoplasia. Cochrane Database Syst Rev. 2013;6: CD003296.

77. Follen M, Atkinson EN, Schottenfeld D, Malpica A, West L, Lippman $\mathrm{S}$, et al. A randomized clinical trial of 4hydroxyphenylretinamide for high-grade squamous intraepithelial lesions of the cervix. Clin Cancer Res Off J Am Assoc Cancer Res. 2001;7:3356-65.

78. Creelan BC, Antonia S, Noyes D, Hunter TB, Simon GR, Bepler $\mathrm{G}$, et al. Phase II trial of a GM-CSF-producing and CD40Lexpressing bystander cell line combined with an allogeneic tumor cell-based vaccine for refractory lung adenocarcinoma. J Immunother. 2013;36:442-50.

79. Higginbotham KB, Lozano R, Brown T, Patt YZ, Arima T, Abbruzzese JL, et al. A phase I/II trial of TAC-101, an oral synthetic retinoid, in patients with advanced hepatocellular carcinoma. J Cancer Res Clin Oncol. 2008;134:1325-35.

80. Griffioen GH, Louie AV, de Bree R, Smit EF, Paul MA, Slotman $\mathrm{BJ}$, et al. Second primary lung cancers following a diagnosis of primary head and neck cancer. Lung Cancer. 2015;S01695002(15):00072. doi:10.1016/j.lungcan.2015.01.011.

81. Vikram B. Changing patterns of failure in advanced head and neck cancer. Arch Otolaryngol. 1984;110:564-5.

82. Hong WK, Lippman SM, Itri LM, Karp DD, Lee JS, Byers RM, et al. Prevention of second primary tumors with isotretinoin in squamous-cell carcinoma of the head and neck. N Engl J Med. 1990;323:795-801.

83. Benner SE, Pajak TF, Lippman SM, Earley C, Hong WK. Prevention of second primary tumors with isotretinoin in patients with squamous cell carcinoma of the head and neck: long-term follow-up. J Natl Cancer Inst. 1994;86:140-1.

84. Khuri FR, Kim ES, Lee JJ, Winn RJ, Benner SE, Lippman SM, et al. The impact of smoking status, disease stage, and index tumor site on second primary tumor incidence and tumor recurrence in the head and neck retinoid chemoprevention trial. Cancer Epidemiol Biomark Prev Publ Am Assoc Cancer Res Cosponsored Am Soc Prev Oncol. 2001;10:823-9.

85. Hildebrandt MA, Lippman SM, Etzel CJ, Kim E, Lee JJ, Khuri $\mathrm{FR}$, et al. Genetic variants in the PI3K/PTEN/AKT/mTOR pathway predict head and neck cancer patient second primary tumor/ recurrence risk and response to retinoid chemoprevention. Clin Cancer Res Off J Am Assoc Cancer Res. 2012;18:3705-13.

86. Zhao J, Fu Y, Liu CC, Shinohara M, Nielsen HM, Dong Q, et al. Retinoic acid isomers facilitate apolipoprotein E production and lipidation in astrocytes through the retinoid $\mathrm{X}$ receptor/retinoic acid receptor pathway. J Biol Chem. 2014;289:11282-92.

87. Endres K, Fahrenholz F, Lotz J, Hiemke C, Teipel S, Lieb K, et al. Increased CSF APPs-alpha levels in patients with Alzheimer disease treated with acitretin. Neurology. 2014;83:1930-5.

88. Nagpal S, Patel S, Jacobe H, DiSepio D, Ghosn C, Malhotra M, et al. Tazarotene-induced gene 2 (TIG2), a novel retinoidresponsive gene in skin. J Investig Dermatol. 1997;109:91-5.

89. Jeon SY, Ha SM, Ko DY, Ku BS, Lee CY, Song KH, et al. Tazarotene-induced gene 3 may affect inflammatory angiogenesis in psoriasis by downregulating placental growth factor expression. Ann Dermatol. 2014;26:517-20.

90. Feldman SR, Werner CP, Alio Saenz AB. The efficacy and tolerability of tazarotene foam, $0.1 \%$, in the treatment of acne vulgaris in 2 multicenter, randomized, vehicle-controlled, double-blind studies. J Drugs Dermatol. 2013;12:438-46.

91. Sandoval LF, Semble A, Gustafson CJ, Huang KE, Levender MM, Feldman SR. Pilot randomized-control trial to assess the effect product sampling has on adherence using adapalene/ benzoyl peroxide gel in acne patients. J Drugs Dermatol. 2014:13:135-40.

92. Humme D, Nast A, Erdmann R, Vandersee S, Beyer M. Systematic review of combination therapies for mycosis fungoides. Cancer Treat Rev. 2014;40:927-33.

93. Schindler M, Drozdenko G, Kuhl AA, Worm M. Immunomodulation in patients with chronic hand eczema treated with oral alitretinoin. Int Arch Allergy Immunol. 2014;165:18-26.

94. Scheinfeld N. Dissecting cellulitis (Perifolliculitis Capitis Abscedens et Suffodiens): a comprehensive review focusing on new treatments and findings of the last decade with commentary comparing the therapies and causes of dissecting cellulitis to hidradenitis suppurativa. Dermatol Online J. 2014;20:22692.

95. Sevrain M, Richard MA, Barnetche T, Rouzaud M, Villani AP, Paul C, et al. Treatment for palmoplantar pustular psoriasis: systematic literature review, evidence-based recommendations and expert opinion. J Eur Acad Dermat Venereol. 2014;28 Suppl 5: 13-6.

96. Dogra S, Yadav S. Acitretin in psoriasis: an evolving scenario. Int J Dermatol. 2014;53:525-38.

97. Karadag AS, Ertugrul DT, Kalkan G, Bilgili SG, Celik HT, Takci $Z$, et al. The effect of acitretin treatment on insulin resistance, retinol-binding protein-4, leptin, and adiponectin in psoriasis vulgaris: a noncontrolled study. Dermatology. 2013;227:103-8.

98. Vahlquist C, Selinus I, Vessby B. Serum lipid changes during acitretin (etretin) treatment of psoriasis and palmo-plantar pustulosis. Acta Derm Venereol. 1988;68:300-5.

99. Angioni AR, Lania A, Cattaneo A, Beck-Peccoz P, Spada A. Effects of chronic retinoid administration on pituitary function. $\mathrm{J}$ Endocrinol Investig. 2005;28:961-4.

100. Bunaciu RP, Tharappel JC, Lehmler HJ, Lee EY, Robertson LW, Bruckner GG, et al. Role of oil vehicle on hepatic cell proliferation 
in PCB-treated rats. J Environ Pathol Toxicol Oncol Off Organ Soc Environ Toxicol Cancer. 2011;30:273-82.

101. Pascoe MC, Howells DW, Crewther DP, Carey LM, Crewther SG. Fish oil supplementation associated with decreased cellular degeneration and increased cellular proliferation 6 weeks after middle cerebral artery occlusion in the rat. Neuropsychiatr Dis Treat. 2015;11:153-64.

102. Bidinotto LT, de Cicco RL, Vanegas JE, Santucci-Pereira J, Vanden Heuvel JP, Washington S, et al. Fish oil alters tamoxifen-modulated expression of mRNAs that encode genes related to differentiation, proliferation, metastasis, and immune response in rat mammary tumors. Nutr Cancer. 2012;64:991-9.
103. Kirimlioglu V, Kirimlioglu H, Yilmaz S, Ozgor D, Coban S, Karadag N, et al. Effect of fish oil, olive oil, and vitamin E on liver pathology, cell proliferation, and antioxidant defense system in rats subjected to partial hepatectomy. Transplant Proc. 2006;38: $564-7$.

104. Anti M, Armelao F, Marra G, Percesepe A, Bartoli GM, Palozza P, et al. Effects of different doses of fish oil on rectal cell proliferation in patients with sporadic colonic adenomas. Gastroenterology. 1994;107:1709-18.

105. Fabbrocini G, Cameli N, Lorenzi S, De Padova MP, Marasca C, Izzo R, et al. A dietary supplement to reduce side effects of oral isotretinoin therapy in acne patients. G Ital Dermatol Venereol Organo Ufficiale, Soc Ital Dermatol Sifilogr. 2014;149:441-5. 